\title{
Recombination of replicon and helper RNAs and the emergence of propagation-competent vectors upon Sindbis virus vector production
}

\author{
ANNA HYVÄRINEN ${ }^{1,2}$, FELICITAS YONGABI ${ }^{1}$, KIMMO MÄKINEN $^{3,4}$, \\ JARMO WAHLFORS ${ }^{1,4,5}$ and RIIKKA PELLINEN ${ }^{1}$
}

\author{
${ }^{1}$ Department of Biotechnology and Molecular Medicine, A.I. Virtanen Institute for Molecular Sciences, \\ University of Eastern Finland, Kuopio; ${ }^{2}$ Department of Surgery, North Karelia Central Hospital, Joensuu; \\ ${ }^{3}$ Department of Surgery, Kuopio University Hospital, Kuopio; ${ }^{4}$ Gene Therapy Unit, \\ Kuopio University Hospital, Kuopio, Finland
}

Received January 27, 2013; Accepted March 21, 2013

DOI: $10.3892 / \mathrm{ijmm} .2013 .1395$

\begin{abstract}
Sindbis vectors have shown remarkable antitumor efficacy and tumor-targeting capacity in animal models and hold promise for cancer therapy. Different packaging systems are used to produce propagation-incompetent Sindbis vectors. However, the vectors produced using either DH-BB single helper RNA or split helper RNA can spread in permissive cell cultures. We investigated the mechanisms of vector spreading and show, here, that recombination occurs between the replicon and DH-BB helper RNA, leading to formation of the full-length virus genome. Split helper RNA may not completely prevent wild-type reversion, although the frequency is greatly reduced. Contrary to propagation of Sindbis DH-BB vectors, Sindbis split helper vectors were frequently able to spread without cytopathic effect (CPE), a feature that was linked to wild-type reversion. Our results support the hypothesis that the non-cytopathic local spreading constantly observed with Sindbis split helper vector results from unspecific packaging of helper RNAs into vector particles and co-infection with particles containing replicon and helper RNAs. Several malignant cell lines with defective interferon responses were found to be permissive for non-cytopathic spreading of the Sindbis split helper vector. Interferon- $\alpha$ suppressed the spreading providing a possible option to control the vector.
\end{abstract}

Correspondence to: Dr Anna Hyvärinen, Department of Biotechnology and Molecular Medicine, A.I. Virtanen Institute for Molecular Sciences, University of Eastern Finland, P.O. Box 1627, Neulaniementie 2, FI-70211 Kuopio, Finland

E-mail: anna.hyvarinen@uef.fi

Present address: ${ }^{5}$ Academic Development Unit, University of Tampere, FI-33014 Tampere, Finland

Key words: Sindbis virus, virus vector, recombination, propagationcompetent virus, alphavirus vector

\section{Introduction}

Sindbis virus-based gene transfer vectors have shown remarkable antitumor efficacy and tumor-targeting capacity in several animal models. After systemic delivery the vector is able to target and destroy tumors without damaging normal tissues. It is efficient in human xenograft tumors, metastatic models as well as in spontaneously arising tumors in immunocompetent animals, making this vector highly attractive for cancer gene therapy research. Importantly, it has been reported that vectors carrying only marker genes can induce efficient systemic tumor cell killing (1-4). In addition, Sindbis virus has been shown to have oncolytic potential $(5,6)$. The Sindbis virus AR339 strain that is non-pathogenic to humans was studied by Unno et al (7) as an oncolytic virus for the treatment of cervical and ovarian cancer with promising results.

Sindbis virus is a member of the alphavirus family. Alphaviruses are enveloped positive strand RNA viruses which typically have a natural life cycle that is comprised of invertebrate (hematophagous insect vectors) and vertebrate hosts (8). The Sindbis virus is the most cosmopolitan of all known alphaviruses, and several of its strains have been isolated throughout the Old World. Birds are primary vertebrate hosts for the Sindbis virus, and infection is transmitted by mosquitos (8). Several laboratory strains of this virus exist, and they have not been reported to cause any human disease (8). The wild-type Sindbis is also usually considered to be non-pathogenic in humans (8), except some strains in Northern Europe and South Africa that cause rash, fever and polyarthritis (8-12). One important characteristic of alphaviruses is that they have a highly plastic genome which helps them to maintain their complex life cycle and adapt to environmental changes that can affect their host species (8). These viruses have the ability for rapid evolution of the receptor binding domains of their envelope glycoproteins, which allows modification of their tropism via continuous passaging (13-16). Genetic flexibility is a general characteristic of RNA-viruses (17). In the case of Sindbis 
virus, template switching by viral RNA-polymerase during negative strand RNA synthesis seems to be a major mechanism of evolution (18).

Several previous studies have suggested that when one of the most commonly used commercially available helpers for Sindbis, DH-BB (19), is used for vector production, propagation-competent viruses are generated at a relatively high frequency (20-22). Lu and Silver (21) demonstrated that after co-electroporation of DH-BB-gfp helper and SinRepLacZ replicon RNAs, the resulting vectors spread locally and produced clusters of cells expressing both marker genes. Furthermore, when a highly sensitive serial passage assay was used, in which the detection of propagation-competent viruses was based on the appearance of a cytopathic effect (CPE), the frequency of propagation-competent virus formation with the DH-BB helper was reported to be as high as $5 \times 10^{-2}(20)$ or $1 \times 10^{-3}(22)$.

In our previous study, we demonstrated that Sindbis vectors produced with a chimeric split helper system (23) can spread locally in BHK-21, BT4C and 9L cell cultures without producing a CPE (20). The split helper system was originally developed to prevent the formation of propagation-competent recombinant viruses during vector production. In the split helper system, the helper RNA containing the structural domain of the Sindbis virus genome is divided into two molecules, one of which (CSin helper) encodes the capsid and the other one (Crrv $\Delta 3$ helper) the envelope genes. However, a translational enhancer element located downstream of the AUG start codon within the capsid sequence is also needed for efficient expression of the envelope genes. In Crrv $\Delta 3$, this enhancer element is replaced with an analogous enhancer of another alphavirus, Ross River virus (23). According to our observations, only the deleted RRV capsid and the Sindbis envelope proteins encoding part of the split helper RNA (Crrv $\Delta 3$ helper) were needed for the generation of the propagating vector. However, when both components of the split helper RNA were used in vector production, the resulting titers were much higher than when the replicon was supported only with the Crrv $\Delta 3$ component of the split helper system (20).

Previous studies have shown that when the Sindbis virus replicon is co-transfected with a helper RNA containing RNA packaging signal, these two RNAs will complement each other and produce infective particles with a bi-partite genome that are able to produce plaques in cultures of permissive cells. Furthermore, co-infection with a wild-type Sindbis virus and the virus with the segmented genome lead to suppression of the wild-type virus (24). However, all of the helper RNA constructs we have used in our studies (single DH-BB helper RNA and the split helper RNAs CSin and Crrv $\Delta 3$ ) lack the RNA packaging signal but nonetheless unspecific packaging of low amounts of these RNAs do occur $(20,21,23)$.

The first evidence of the recombination between Sindbis virus RNAs was published by Geigenmüller-Gnirke et al (24). Weiss and Schlesinger (25) sequenced the junction region of several recombinants that emerged after co-transfection of different parental Sindbis RNAs. Sequencing of the crosses revealed that recombination may produce sequence rearrangements, deletions or insertions derived from parental RNAs or of cellular origin. According to their studies, sequence homology-independent recombination events between Sindbis virus replicon and helper RNAs occur frequently, although only the recombinants with crosses that preserve the nsP genes as well as the structural protein genes are viable and can be isolated.

Interferons (IFNs) are cytokines that are induced by viral or bacterial infections. Type I IFNs (IFN- $\alpha / \beta)$ are produced in direct response to viral infection by infected cells. In surrounding cells, they trigger a signaling cascade leading to expression of IFN-inducible genes (26). Consequently, the cells develop an antiviral state, whereby the replication of the virus is inhibited via several IFN-inducible pathways, e.g. dsRNA-dependent protein kinase R (PKR), 2'-5' oligoadenylate synthetases (OAS) leading to activation of RNase $\mathrm{L}$ and myxovirus resistance $(\mathrm{Mx})$ proteins. Moreover, IFNs modulate the functions of various cell types, leading to more effective and better directed immune responses (27). However, viruses have developed several strategies for inhibition of the host IFN response. Usually these strategies cannot completely eliminate the effects of the IFNs, since cells have multiple parallel pathways for IFN induction and transcriptional initiation of IFN-induced genes, which in turn encode proteins or enzymes that are able to suppress viral replication by several unrelated means. This reflects the crucial importance of the IFN response to the host immune defense (27).

The aim of this study was to investigate the features of propagation-competent vectors emerging upon Sindbis virus vector production and to study whether recombination between the replicon and helper RNAs could occur, possibly leading to wild-type reversion of the vector. Furthermore, we tested human osteosarcoma and rhabdomyosarcoma cell lines as targets for a Sindbis vector and investigated the role of IFN response as a limiting factor for vector propagation.

\section{Materials and methods}

Cell lines. BHK-21 baby hamster kidney cells (ATCC CCL-10), BT4C rat glioma cells (28), TE-671 human rhabdomyosarcoma cells (ATCC CCL-136) and three human osteosarcoma cell lines MG-63 (ATCC CRL-1427), U-2-OS (ATCC HTB-96) and Saos-2 (HTB-85) were all grown in Dulbecco's modified Eagle's medium (DMEM) with $10 \%$ fetal calf serum (FCS) and $50 \mu \mathrm{g} / \mathrm{ml}$ gentamycin at $37^{\circ} \mathrm{C}$ and $5 \% \mathrm{CO}_{2}$.

Production of Sindbis virus vectors. A TKGFP fusion gene containing Sindbis virus replicon construct pSin-TKGFP (22) was used in this study for vector production. The backbone of the pSin-TKGFP construct is pSinRep5 (Invitrogen Life Technologies, Carlsbad, CA, USA). We used two different helper systems: the single component DH-BB helper plasmid (Invitrogen Life Technologies) and the split helper system plasmids DH-BBCSin (CSin helper) and DH-BBCrrv $\triangle 3 E 1 E 2$ (Crrv $\Delta 3$ helper) as described previously (23). The first split helper component contains Sindbis virus capsid gene and the second component is a chimera of an extensively deleted Ross River virus capsid gene and Sindbis virus envelope encoding sequences (PE2, 6K and E1).

Linearized plasmids were used as templates for in vitro RNA synthesis with SP6 RNA polymerase (Amersham 


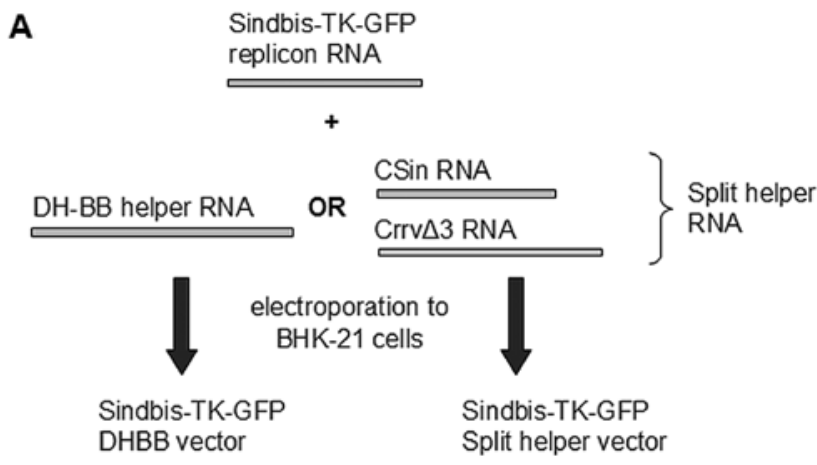

B Transduction of BHK-21 cells with a Sindbis virus vector

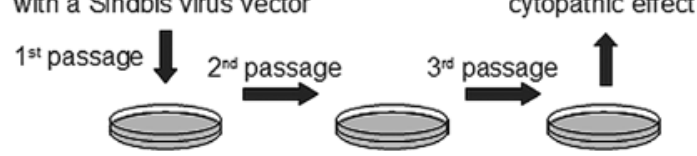

Figure 1. (A) Vector production with DH-BB and split helper RNAs. (B) Serial passage of Sindbis virus vectors in BHK-21 cells and detection of the cytopathic effect indicating the presence of propagation-competent virus.

Biosciences China). The reaction was performed in $40 \mu 1$ volume containing $5 \mu 1$ 10X SP6 buffer (Amersham), $2.5 \mu \mathrm{g}$ template DNA, $5 \mu 150 \mathrm{mM}$ DTT (Promega, Madison, WI, USA), $5 \mu \mathrm{l}$ volume of $5 \mu \mathrm{M}$ rNTP mixture (100 mM ATP, CTP, UTP and GTP), $5 \mu 110 \mathrm{mM} \mathrm{CAP}\left[\mathrm{m}^{7} \mathrm{G}\left(5^{\prime}\right) \mathrm{ppp}\left(5^{\prime}\right) \mathrm{G}\right]$ and $1.5 \mu \mathrm{l}$ RNase inhibitor (all from Roche). After a 2-h incubation at $37^{\circ} \mathrm{C}, 50 \mu 18 \mathrm{M} \mathrm{LiCl}$ and $60 \mu 1$ sterile $\mathrm{H}_{2} \mathrm{O}$ were added, and RNA was precipitated o/n at $-20^{\circ} \mathrm{C}$. RNA was pelleted and washed with $70 \% \mathrm{EtOH}$, air dried and resuspended in sterile $\mathrm{H}_{2} \mathrm{O}$ (Aquasteril; Baxter). The RNA preparations were stored at $-70^{\circ} \mathrm{C}$ before use.

Ten or forty micrograms of each RNA species (Fig. 1A) was electroporated in equal amounts to logarithmically growing BHK-21 cells. Supernatants containing the vectors were collected $24 \mathrm{~h}$ later, purified using a $0.2-\mu \mathrm{m}$ cellulose acetate filter (Whatman $\mathrm{GmbH}$, Germany) and stored in aliquots at $-70^{\circ} \mathrm{C}$.

Vector titers were determined essentially as described previously (22). Logarithmically growing BHK-21 cells were split onto 12 -well plates $\left(2 \times 10^{5}\right.$ cells/well $)$ and incubated at $37^{\circ} \mathrm{C}$ for $4 \mathrm{~h}$ allowing the cells to attach. Cells were transduced in duplicate with serial dilutions of vector supernatants prepared in Opti-MEM ${ }^{\circledast}$ I with GlutaMAX ${ }^{\mathrm{TM}}$ I medium (Gibco, GB) for $1 \mathrm{~h}$ at $37^{\circ} \mathrm{C}$. Then $1.5 \mathrm{ml}$ growth medium was added onto each well and the incubation was continued for $6 \mathrm{~h}$. The cells were harvested and fixed with $4 \%$ paraformaldehyde, and the proportion of GFP-expressing cells was determined using flow cytometry (FACSCalibur, BectonDickinson). Titers were calculated based on the proportion of transgene-positive viable cells, the cell number at the time of transduction and the dilution factor of the vector supernatant.

Serial passage assay. Virus preparations were tested for propagation-competent viruses by a method based on observing the CPE after serial passaging in BHK-21 cells (Fig. 1B). Transductions were carried out in triplicates on 12-well plates in a 300- $\mu 1$ volume of Opti-MEM I with GlutaMAX I medium for $1 \mathrm{~h}$, followed by addition of $700 \mu \mathrm{l}$ growth medium. For transductions (1st passage), seven 5 -fold serial dilutions of Sindbis-TKGFP split helper or Sindbis-TKGFP DH-BB vectors were used. The highest MOIs used in this assay were 0.04 with Sindbis-TKGFP split helper and 0.05 with Sindbis-TKGFP DH-BB vectors. After 2 days of incubation at $37^{\circ} \mathrm{C}, 500 \mu \mathrm{l}$ supernatant from each well was passaged onto fresh BHK-21 cells (2nd passage) growing on 12-well plates $\left(2 \times 10^{5}\right.$ cells $/$ well $)$ in a $0.5-\mathrm{ml}$ volume of growth medium. These cells were incubated for 2 days and the supernatants were passaged again onto fresh BHK-21 cells (3rd passage), as described above. The frequency of propagation-competent virus in each preparation was calculated based on the virus titer and the last dilution yielding complete CPE (more than $90 \%$ of cells dead based on microscopy) at least in two of the three parallel wells. To study the kinetics of the vector spreading, we observed the $\mathrm{CPE}$ also on plates from previous passages and then fixed the cells with $4 \%$ paraformaldehyde for fluorescence microscopy. Clusters of TKGFP-expressing cells were counted in each well.

Plaque titration assay. For plaque titration, BHK-21 cells were split on 24-well plates $\left(5 \times 10^{4}\right.$ cells/well) and incubated $\mathrm{o} / \mathrm{n}$ at $37^{\circ} \mathrm{C}$. On the following day, the cells were transduced with serial dilutions of the vector (6 parallel wells for each dilution) in a $200-\mu \mathrm{l}$ transduction volume for $1 \mathrm{~h}$ followed by overlaying the cells with $0.4 \%$ SeaPlaque agarose in growth medium $\left(0.5 \mathrm{ml} /\right.$ well). Plates were incubated at $37^{\circ} \mathrm{C}$ for $48 \mathrm{~h}$. The cells were fixed and stained o/n at $37^{\circ} \mathrm{C}$ using solution containing $5 \%$ formalin, $1 \% \mathrm{EtOH}$ and crystal violet $(2 \mathrm{~g} / \mathrm{l})$ in PBS. The agarose was then removed by inverting and knocking the plates on the desk. Plaques were counted and titers were determined. For comparison, plaque titers were also determined for a Sindbis-TKGFP DH-BB vector preparation containing $2 \times 10^{7} \mathrm{TU} / \mathrm{ml}$ (titer based on the flow cytometry titration).

Fluorescence microscopy for detection of localized noncytopathic propagation. MG-63, Saos-2, U-2-OS, TE-671 and BHK-21 cells were split on 12 -well plates $\left(5 \times 10^{4}\right.$ cells/well). On the following day, cells were transduced with SindbisTKGFP split helper vector (MOI 0.7) (medium: Opti-MEM I with GlutaMAX I) in a $0.3-\mathrm{ml}$ transduction volume for $1 \mathrm{~h}$ and then $1.5 \mathrm{ml}$ growth medium was added onto each well. Cells were incubated for $48 \mathrm{~h}$ at $37^{\circ} \mathrm{C}$ followed by fixation with $4 \%$ paraformaldehyde and inspected by fluorescence microscopy. Clusters of TKGFP-expressing cells indicating local spreading of the vector were photographed (bright field and fluorescence images).

PCR and cloning of PCR products for sequencing of recombination sites. The potential recombination sites were amplified with PCR using primers described in Table I and Fig. 2. Sindbis-TKGFP DH-BB and split helper vectors and the Sindbis split helper $\mathrm{CPE}^{+}$supernatant were used to infect BHK-21 cells followed by overlaying with agarose (see above). Single plaques were isolated at the $48 \mathrm{~h}$ time-point and used to infect logarithmically growing BHK-21 cells on $10-\mathrm{cm}$ plates. After a 24-h incubation, total cellular RNA was extracted 
Table I. PCR primers.

\begin{tabular}{|c|c|c|c|}
\hline Number & Orientation & Binding site in Sindbis virus genome & Sequence \\
\hline 1 & $\mathrm{~F}$ & 7097-7114, nsP4 & 5'-CGT TAT CGC CAG CAG AGT-3' \\
\hline 2 & $\mathrm{R}$ & 9750-9766, E2 & 5'-ATC ATC GCC ACG GTA GC-3' \\
\hline 3 & $\mathrm{~F}$ & 11018-11036, E1 & 5'-GCA GTA TGT ATC CGA CCG C-3' \\
\hline 4 & $\mathrm{R}$ & 1167-1188, nsP1 & 5'-TGT TCC TGT TAG TCC TAC CGT T-3' \\
\hline 5 & $\mathrm{~F}$ & 684-701, nsP1 & 5'-CGT AAC ATC GGA CTT TGC-3' \\
\hline 6 & $\mathrm{~F}$ & 796-818, nsP1 & 5'-CGA CAC TTT ATC CAG AAC ACA GA-3' \\
\hline 7 & $\mathrm{R}$ & $8005-8022, \mathrm{C}$ & 5'-TGA CAT CTC CGT CCT CGT-3' \\
\hline 8 & $\mathrm{~F}$ & 7786-7800, C & 5'-CAG CCG TCA GTG CCC-3' \\
\hline 9 & $\mathrm{~F}$ & $8140-8156, \mathrm{C}$ & 5'-AGT TCG CAC AGT TGC CA-3' \\
\hline
\end{tabular}

$\mathrm{F}$, forward; R, reverse.

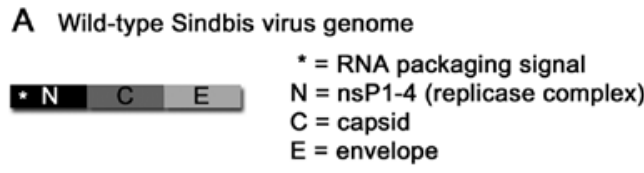

B Sindbis vector genome

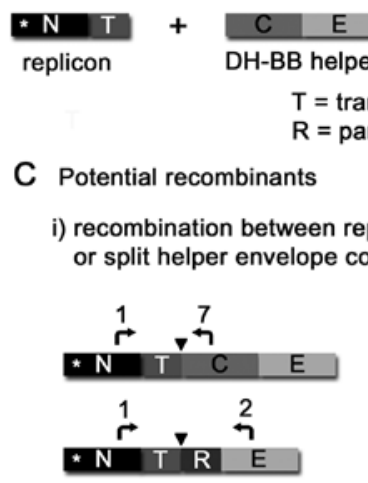

\section{OR}

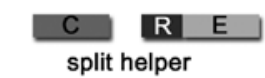

split helper

$=$ transgene

$\mathrm{R}=$ partially deleted $\mathrm{RRV}$ capsid

C Potential recombinants

recombination between replicon and $\mathrm{DH}-\mathrm{BB}$ helper

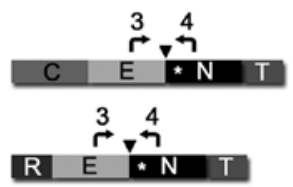

ii) acquisition of nsP1 derived RNA packaging signal (or nsP1-4 genes) by helper RNAs
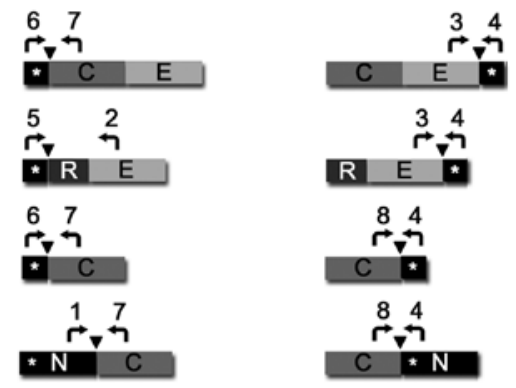

iii) recombination between split helper components
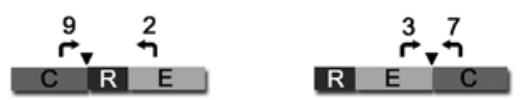

Figure 2. Primers designed for PCR of potential recombination sites. (A) Wild-type Sindbis genome, (B) replicon and helper RNAs and (C) potential recombinants. i) Recombination between the replicon and $\mathrm{DH}-\mathrm{BB}$ helper or the envelope-containing component of the split helper $(\operatorname{Crrv} \Delta 3)$ leads to the formation of propagation-competent virus. ii) Acquisition of the RNA packaging signal by helper RNAs leads to the formation of bipartite propagation-competent virus genome along with the replicon RNA. iii) Recombination of the split helper components may increase the risk of wild-type reversion to levels similar to those with DH-BB helper RNA. with TRIzol according to the manufacturer's instructions. RNAs were stored at $-70^{\circ} \mathrm{C}$ until cDNA synthesis $(1.5 \mu \mathrm{g}$ RNA for each reaction) with $0.25 \mu \mathrm{g}$ random hexamer primers, 40 units M-MuLV reverse transcriptase (both from Promega) and 20 units RiboLock ribonuclease inhibitor (Fermentas). RNA was incubated with random hexamer primers in a $11-\mu 1$ volume at $70^{\circ} \mathrm{C}$ for $5 \mathrm{~min}$, chilled on ice and mixed with other reagents in total reaction volume of $21 \mu \mathrm{l}$, followed by incubations at $25^{\circ} \mathrm{C}$ for $10 \mathrm{~min}$, at $37^{\circ} \mathrm{C}$ for $60 \mathrm{~min}$ and at $70^{\circ} \mathrm{C}$ for $10 \mathrm{~min}$ (termination of the reaction). The cDNAs were stored at $-20^{\circ} \mathrm{C}$. The cDNAs were used as templates for PCR reactions with 1 unit DynaZyme DNA polymerase, $0.5 \mu 110 \mathrm{mM}$ dNTP (both from Finnzymes), 10 pmol of both primers and $2.5 \mu \mathrm{l}$ template cDNA. PCR conditions consisted of: $96^{\circ} \mathrm{C}$ for $30 \mathrm{sec}, 60^{\circ} \mathrm{C}$ (for all primer pairs) or $63^{\circ} \mathrm{C}$ (additional optimized reactions for primer pairs $1+7$ and $9+2$ ) for $1 \mathrm{~min}$, and $72^{\circ} \mathrm{C}$ for $1 \mathrm{~min}$, for 30 cycles. The PCR products were then fractionated with agarose gel electrophoresis ( $0.9 \%$ agarose in TAE buffer with $\mathrm{EtBr})$ and each product was extracted using Qiagen MinElute Gel extraction kit according to the manufacturer's instructions. The fragments were then cloned into pCR-XL-TOPO plasmid using the TOPO $^{\circledR}$ XL PCR Cloning kit (Invitrogen Life Technologies), according to the manufacturer's instructions, transformed into competent DH5 $\alpha$ E. coli cells and plated on LB agar plates with kanamycin $(50 \mu \mathrm{g} / \mathrm{ml})$. After $\mathrm{o} / \mathrm{n}$ incubation at $37^{\circ} \mathrm{C}$, single colonies were selected for further analysis. Plasmids were purified using the QIAprep Spin Miniprep kit (Qiagen) according to the microcentrifuge protocol for plasmid DNA. The inserts were sequenced using M13 R and M13 F (-20) primers included in the TOPO XL PCR Cloning kit.

Determination of transduction efficiency and type I IFN response. TE-671, BT4C, U-2-OS, MG-63 and Saos-2 cells were split onto 6 -well plates $\left(1.5 \times 10^{5}\right.$ cells/well $)$ and incubated at $37^{\circ} \mathrm{C} \mathrm{o} / \mathrm{n}$. On the following day, the cells were transduced with Sindbis-TKGFP split helper vector (titer $2.3 \times 10^{6} \mathrm{TU} /$ ml) (MOI 0.4) in Opti-MEM I with GlutaMAX I medium (or medium only for controls) in a 1-ml transduction volume for $4 \mathrm{~h}$, and then $2 \mathrm{ml}$ growth medium was added to each well. The cells were harvested for flow cytometry (FACSCalibur, Becton-Dickinson) and for western blotting 24, 48 and $72 \mathrm{~h}$ 
Table II. Loss of TKGFP transgene expression during continued passaging of Sindbis-TKGFP vectors produced with the split helper RNAs.

\begin{tabular}{|c|c|c|c|c|c|c|}
\hline \multirow{2}{*}{$\begin{array}{l}\text { Serial passage } \\
\text { assay no. }\end{array}$} & \multicolumn{2}{|c|}{$\begin{array}{l}\text { Proportion of wells } \\
\text { containing clusters of } \\
\text { transgene-expressing cells }\end{array}$} & \multicolumn{2}{|c|}{$\begin{array}{l}\text { Proportion of wells } \\
\text { containing only single } \\
\text { transgene-expressing cells }\end{array}$} & \multicolumn{2}{|c|}{$\begin{array}{c}\text { Proportion of } \\
\text { wells negative for } \\
\text { transgene-expression }\end{array}$} \\
\hline & 1st passage & 3rd passage & 1st passage & 3rd passage & 1st passage & 3rd passage \\
\hline 1 & $9 / 21(42.9 \%)$ & $3 / 21(14.3 \%)$ & $0 / 21(0 \%)$ & $1 / 21(4.8 \%)$ & $12 / 21(57.1 \%)$ & $17 / 21(81.0 \%)$ \\
\hline 2 & $7 / 21(33.3 \%)$ & $2 / 21(9.5 \%)$ & $5 / 21(23.8 \%)$ & $0 / 21(0 \%)$ & $9 / 21(42.9 \%)$ & $19 / 21(90.5 \%)$ \\
\hline
\end{tabular}

after transduction. Flow cytometry samples were fixed with $4 \%$ paraformaldehyde, and the proportion of GFP-expressing cells was determined.

For western blotting, cell pellets were stored at $-70^{\circ} \mathrm{C}$. Proteins were extracted and MxA western blot analyses were performed as previously described (29). Briefly, $30 \mu \mathrm{g}$ of the protein samples were denatured and run on $12.5 \%$ SDS-PAGE gel using a Laemmli buffer system. As a positive control, we used A549 cells incubated with medium containing $10 \mathrm{U} / \mathrm{ml}$ human recombinant interferon- $\alpha \mathrm{A} / \mathrm{D}$ for $48 \mathrm{~h}$ before sampling. A549 cells have been previously shown to express MxA as a response to type I IFNs (30). An equal amount of protein from the positive control samples was loaded onto each gel. Proteins were transferred onto Invitrolon $^{\text {TM }}$ PVDF membranes (45- $\mu \mathrm{m}$ pore size; Invitrogen Life Technologies), and membranes were incubated in blocking solution o/n at $4^{\circ} \mathrm{C}$. Then membranes were incubated with primary rabbit anti-MxA antibody (31) using a 1:2,000 dilution for $1 \mathrm{~h}$ at RT, washed 3 times and then incubated with secondary peroxidase (HRP)-conjugated donkey anti-rabbit IgG antibody (Amersham Biosciences, Little Chalfont, UK) using a 1:200,000 dilution for $1 \mathrm{~h}$ at RT. Membranes were washed 4 times before chemiluminescence detection with the ECL $^{\mathrm{TM}}$ Plus Western Blotting Detection System (Amersham Biosciences), according to the manufacturer's instructions. MxA western blotting could not be used for BT4C rat glioma cells because of the differences between human and rat Mx proteins. The type I interferon response in these cells was studied by blocking vector spreading with IFN- $\alpha$ (as described below).

Blocking the vector propagation with IFN- $\alpha$. BHK-21 or BT4C cells were split on 24 -well plates $\left(5 \times 10^{4}\right.$ cells/well). The plates were incubated at $37^{\circ} \mathrm{C}$ for $4 \mathrm{~h}$ (BHK-21) or o/n (BT4C) to allow the cells to attach. Cells were transduced with SindbisTKGFP Split helper vector in Opti-MEM I with GlutaMAX I in a 0.3 -ml transduction volume for $1 \mathrm{~h}$ using MOIs 0, 0.005, 0.05 and 0.5 for BHK-21 or MOIs $0,0.003,0.03$ and 0.3 for BT4C cells. Then $300 \mu 1$ growth medium containing IFN- $\alpha$ (IFN- $\alpha$-A/D, human recombinant expressed in E. coli; SigmaAldrich, St. Louis, MO, USA) at different concentrations was added. Final concentrations in the wells were $1,000,100$, 10,1 or $0 \mathrm{U} / \mathrm{ml} \mathrm{IFN}-\alpha$ for BHK-21 cells and $1,000,100$ or $0 \mathrm{U} / \mathrm{ml}$ IFN- $\alpha$ for BT4C cells. The cells were incubated at $37^{\circ} \mathrm{C}$ for $48 \mathrm{~h}$ and fixed with $4 \%$ paraformaldehyde for fluorescence microscopy or harvested for flow cytometry. Vector spreading was analyzed with fluorescence microscopy (bright field and fluorescence photographs). Flow cytometry samples were fixed with $4 \%$ paraformaldehyde and analyzed to determine the proportion of TKGFP transgene-expressing cells.

\section{Results}

Detection of propagation-competent virus. Serial passage assays for the Sindbis-TKGFP DH-BB vector revealed a constant formation of propagation-competent viruses that produced complete CPE (more than $90 \%$ of cells appeared dead by microscopy). The assay was carried out twice and both analyses revealed that in a large proportion of the wells displaying CPE during the third passage, the cells no longer expressed GFP. In the first serial passage assay, GFP expression was found in only $22 \%$ of the wells presenting CPE during the third passage, whereas GFP was expressed in 33\% of the corresponding wells during the first passage. In the second assay, the respective proportions of wells with GFP expression were 0\% (3rd passage) and 100\% (1st passage). These results suggest that in the context of the propagation-competent vector, the presence of the transgene was unstable and the variants lacking the relatively large TKGFP transgene had a positive selection advantage over those with preserved transgene expression capacity.

Serial passage assays for Sindbis-TKGFP split helper vector showed only occasional $\mathrm{CPE}$ that was considerably milder (approximately $50 \%$ of cells were dead) than that observed with the Sindbis-TKGFP DH-BB vector. Thus, because this was suggestive of formation of the propagation-competent virus, the supernatant was collected from a well presenting with CPE for further studies (Sindbis split helper $\mathrm{CPE}^{+}$supernatant). The appearance of $\mathrm{CPE}$ due to the presence of propagation-competent viruses or virus-like particles in the cell cultures infected with Sindbis split helper vectors was too rare an event for reliable detection of the frequency of this phenomenon with the serial passage assay. In both instances when the assay was performed, one or two wells out of three were CPE-positive with the second dilution (MOI 0.008 or 0.007 ) but the wells infected with the 5 -fold more concentrated first dilution remained all CPE-negative. However, local propagation of TKGFP transgene-carrying vector without associated $\mathrm{CPE}$ (indicated by clusters of viable green fluorescent cells) was noted in the serial passage assays far more frequently. Sometimes, the TKGFP-expressing cell clusters were detected also after two passages but in most 
Table III. Wild-type reversion according to the sequence of the PCR products.

\begin{tabular}{llll}
\hline Vector & \multicolumn{2}{c}{ Primers } & \\
\cline { 2 - 3 } Sindbis DH-BB & Forward & Reverse & \multicolumn{1}{c}{ Recombination } \\
Sindbis split helper $\mathrm{CPE}^{+}$ & $1(\mathrm{nsP} 1)$ & $7(\mathrm{C})$ & $\begin{array}{l}\text { Restoration of wild-type junction between the non-structural } \\
\text { and structural open reading frames due to recombination of } \\
\text { replicon and DH-BB helper }\end{array}$ \\
Sindbis split helper $\mathrm{CPE}^{+}$ & $9(\mathrm{C})$ & $\begin{array}{l}\text { Restoration of wild-type junction between the non-structural } \\
\text { and structural open reading frames due to recombination of } \\
\text { replicon and CSin helper }\end{array}$ \\
& & $2(\mathrm{E} 2)$ & $\begin{array}{l}\text { Restoration of wild-type structural open reading frame } \\
\text { sequence due to recombination of split helper components }\end{array}$
\end{tabular}

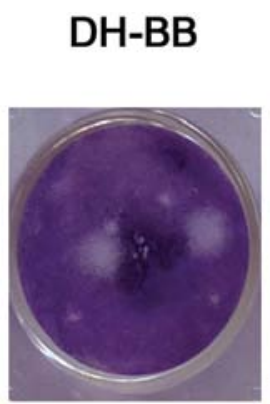
(CPE+)

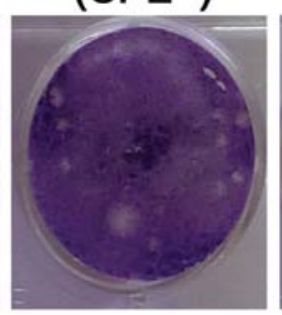

\section{Split helper}

Split helper

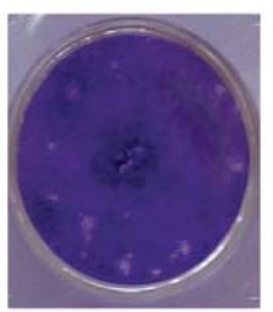

Figure 3. Typical appearance of plaques after infection with the Sindbis $\mathrm{DH}-\mathrm{BB}$ vector, Sindbis split helper $\mathrm{CPE}^{+}$supernatant and standard produced Sindbis split helper vector. With the Sindbis DH-BB vector and Sindbis split helper $\mathrm{CPE}^{+}$supernatant, large- and intermediate-sized plaques were present, respectively. Infection with the Sindbis split helper vector gave rise to pinpoint-sized plaques.

cases, the clusters disappeared when the supernatant was passaged twice (Table II).

Flow cytometry and plaque titers. Flow cytometry titer of the Sindbis-TKGFP DH-BB vector, that was produced according to the standard procedure, was $2 \times 10^{7} \mathrm{TU} / \mathrm{ml}$ and the plaque titer was $4 \times 10^{3} \mathrm{pfu} / \mathrm{ml}$. The supernatant collected from cells infected with the Sindbis split helper $\mathrm{CPE}^{+}$supernatant (see above) was also titrated by using both flow cytometry and the plaque titration assay. Flow cytometry titer could not be determined as no GFP expression was detected in the virus-infected cells. However, the plaque titration assay from the supernatant revealed titers as high as $5.8 \times 10^{6} \mathrm{pfu} / \mathrm{ml}$. Most plaques were pinpoint-sized but also large plaques were present; their sizes close to the average size of the plaques observed with the Sindbis-TKGFP DH-BB vector. Large plaques produced a titer of $4.2 \times 10^{5} \mathrm{pfu} / \mathrm{ml}$. These results indicate that propagation-competent vectors that no longer carried the TKGFP transgene had a significant selection advantage over those containing the functional TKGFP expression casette.

PCR and sequencing of the recombination sites. Using Sindbis DH-BB vectors and Sindbis split helper $\mathrm{CPE}^{+}$supernatant, the selection of propagation-competent vectors which were no longer capable of transgene expression during serial passaging suggested that recombination could play a role in acquisition of propagation competence. To detect possible recombinants, cells were infected with the Sindbis split helper $\mathrm{CPE}^{+}$supernatant and vectors produced with $\mathrm{DH}-\mathrm{BB}$ or split helper RNAs and overlaid with agarose. All vectors gave rise to plaques, although with standard produced Sindbis split helper only pinpoint-sized plaques were present (Fig. 3) Single plaques were isolated and used to infect fresh cells for RNA extraction and rtPCR. A series of different PCR primers annealing to Sindbis virus genome were designed (Table I and Fig. 2). In each primer pair, forward and reverse primers were located in distinct vector RNAs (replicon and helper RNAs or in the two components of the split helper RNA) in such a way that possible recombination would lead to amplification of the recombination site. PCR amplification with any single primer pair gave rise to multiple PCR products of variable sizes. After agarose gel electrophoresis, the different PCR products were extracted from the gel and cloned for subsequent sequencing of the recombination sites. The PCR products that, based on their size, were suggestive of wild-type reversion of the virus due to recombination of replicon and helper RNAs or both components of the split helper, were chosen to be sequenced. We could verify restoration of the wild-type junction between the structural and non-structural open reading frames in both the Sindbis DH-BB and Sindbis split helper $\mathrm{CPE}^{+}$samples. Furthermore, restoration of the complete wild-type structural open reading frame was verified in the case of Sindbis split helper $\mathrm{CPE}^{+}$. The results are summarized in Figs. 4 and 5 and Table III. In addition, some of the other PCR products were sequenced. These represented either unspecific binding of the primers or replicon-helper recombinants with some type of deletion extending over the junction area between the nonstructural and structural open reading frames. The alternative deletions that were found represented nucleotides 7355 to 9626,7292 to 9735,830 to 8442,817 to 9553 and 869 to 9567 in the wild-type Sindbis virus genome. Notably, some of the Sindbis split helper $\mathrm{CPE}^{+}$plaques did not contain sequences indicating wild-type reversion of the virus. Moreover, some of the plaques arising from infection by the standard produced Sindbis split helper vector completely failed to give rise to PCR products with the used primers. 


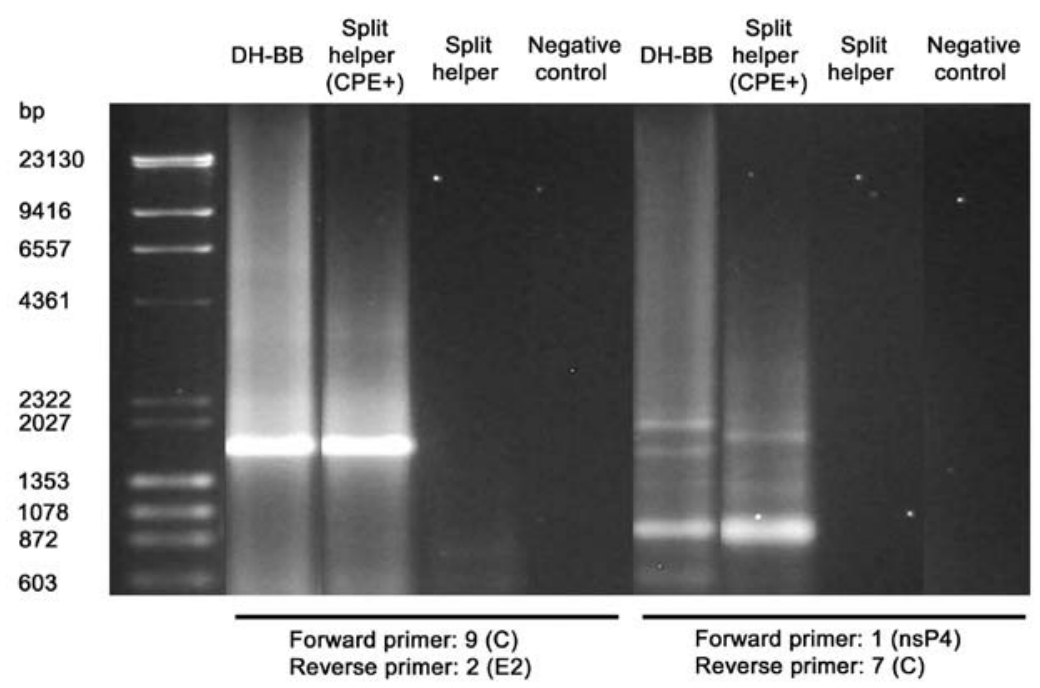

Figure 4. PCR analysis of the Sindbis DH-BB and Sindbis split helper $\left(\mathrm{CPE}^{+}\right)$vectors. PCR from single plaques with primers binding to nsP4 and capsid (C) sequences resulted in the formation of PCR products that seemed to be attributable to recombination and wild-type reversion of the non-structural and structural open reading frame junction. Similar analysis of the Sindbis split helper vector showed no PCR products, suggesting no recombination between the replicon and CSin helper RNA. PCR from the same plaques with primers binding to C and E2 yielded a PCR product when Sindbis DH-BB was analyzed, indicating packaging of the DH-BB helper to vector particles, and a similar PCR product was formed when the Sindbis split helper (CPE') sample was analyzed, suggesting recombination between the split helper components. Again, the Sindbis split helper vector analyzed with the same primers provided no evidence of recombination.

A

\begin{tabular}{|l|l|l|l|llll}
\hline & & & & & & & \\
\hline$n s P 1$ & $n s P 2$ & $n s P 3$ & $n s P 4$ & capsid E3 & E2 & 6K & E1
\end{tabular}

B
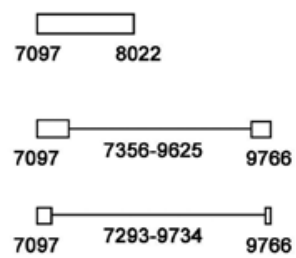

C

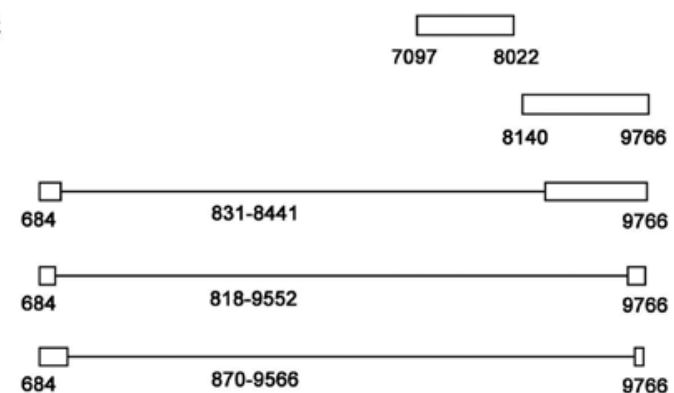

Figure 5. Sequencing of the PCR products. (A) Full-length Sindbis genome. Sequencing of the PCR products from Sindbis DHBB revealed restoration of the wild-type junction between the non-structural and structural open reading frames. (B) Additionally, two different recombinants with deletions extending over the junction area between the non-structural and structural open reading frames are shown. (C) Sequencing of the PCR products from Sindbis split helper $\mathrm{CPE}^{+}$showed restoration of the wild-type sequence extending over the junction of the non-structural and structural open reading frames as well as restoration of the wild-type structural open reading frame sequence due to recombination between the split helper components.

Local non-cytopathic spreading in human osteosarcoma and rhabdomyosarcoma cells. Transduction of cells with the Sindbis-TKGFP split helper vector revealed that 2 out of the 5 cell lines studied (MG-63 and Saos-2) were relatively resistant to both transduction and propagation of the Sindbis virus vector (Fig. 6). Some localized propagation was noted in the human osteosarcoma cell line U-2-OS, whereas in TE-671 human rhabdomyosarcoma cells, local spreading of the vector was frequently detected. In the BHK-21 cells, the Sindbis-TKGFP split helper vector was able to spread throughout the cell culture (Fig. 6, bottom panel).

Transduction efficiency. In all of the studied cell lines, the best transduction efficiency was achieved at $24 \mathrm{~h}$ after transduction with the Sindbis-TKGFP split helper vector, followed by a decline in the proportion of transgene-expressing cells (Fig. 7). We previously demonstrated that the Sindbis-TKGFP split helper vector spreads locally in BT4C rat glioma cells (20). The average size of the propagation foci in the BT4C cells was comparable to that in the TE-671 cells, and these two cell lines also demonstrated the highest numbers of transgene-positive cells at the $24 \mathrm{~h}$ time-point of all cell lines tested. The gene expression declined slower in these two cell lines that were displaying frequent local spreading of the vector, compared to the other cell lines.

Effect of type I IFN response to vector spreading. Induction of type I IFN response after transduction with the SindbisTKGFP split helper vector was studied with MxA expression analysis by western blotting (Fig. 7). IFN- $\alpha / \beta$-induced MxA protein accumulation is commonly used as a biomarker for the induction of a type I IFN response (31). Only one of the cell lines studied, the human osteosarcoma cell line MG-63, exhibited a strong IFN response against this vector (Fig. 7) and no vector spreading was demonstrated in these cells (Fig. 6). In the other cell lines tested (Saos-2, U-2-OS and TE-671) no evidence was detected for any type I IFN response, according to the results of the MxA western blot analyses (Fig. 7). 


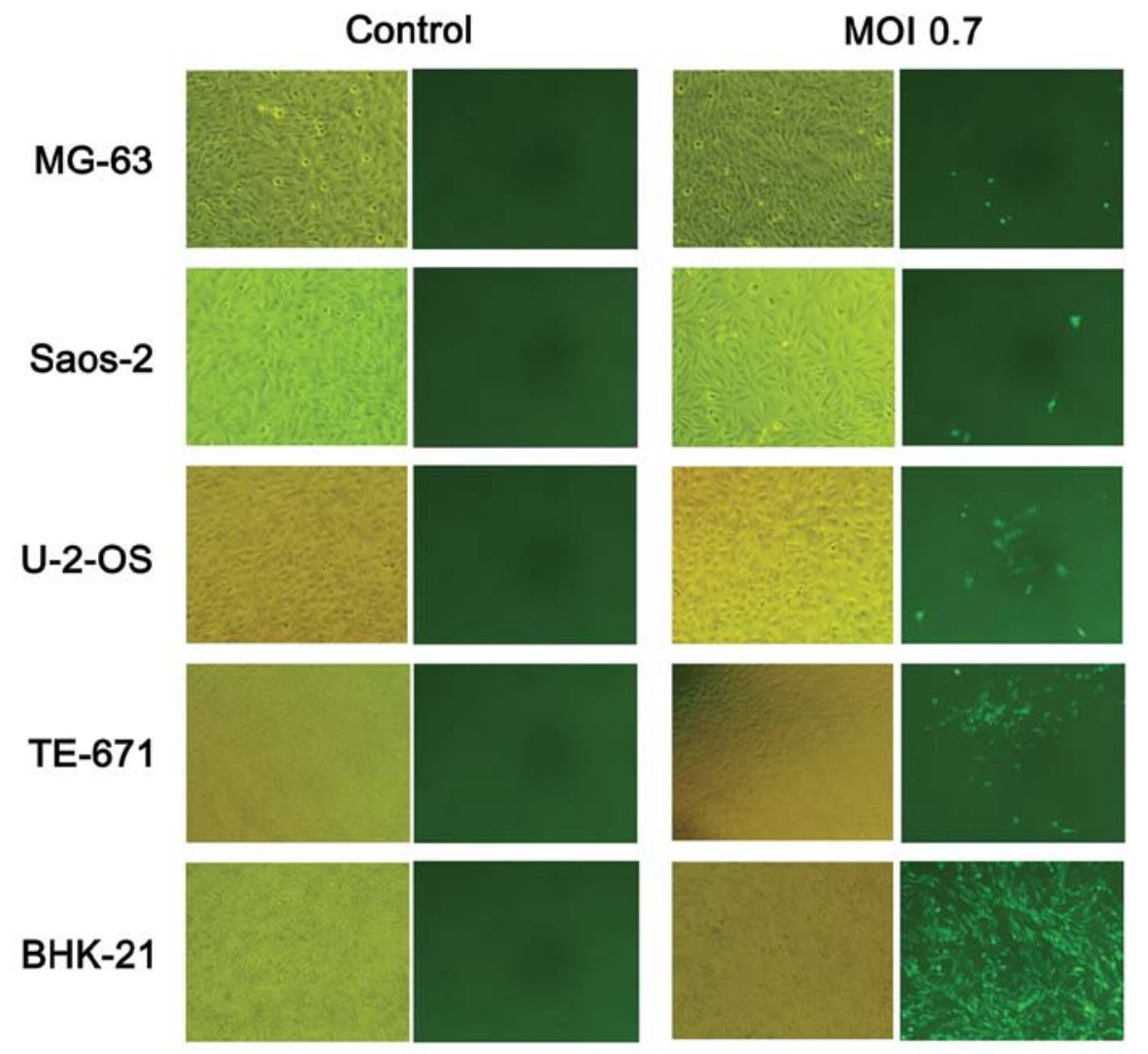

Figure 6. Fluorescence microscopy of 5 cell lines $48 \mathrm{~h}$ after transduction with the Sindbis-TKGFP vector that was produced with the split helper RNAs. Clusters of TKGFP transgene-expressing cells indicating local spreading of the vector were found in U-2-OS and TE-671 cell cultures. When MOI 0.7 was used, single spreading foci were not identified in the BHK-21 cell culture due to the high proportion of transgene expressing cells. No local spreading was observed in the MG-63 and Saos-2 human osteosarcoma cells.

To confirm the negative impact of a type I IFN response on vector spreading, we transduced BHK-21 and BT4C cells with Sindbis-TKGFP split helper vectors for $1 \mathrm{~h}$ and added IFN- $\alpha$-containing growth medium to the cells. The presence of IFN- $\alpha$ in the growth medium effectively inhibited vector spreading in the BHK-21 cells, which themselves produce little or no IFN (32) (Fig. 8). An inhibitory effect of IFN- $\alpha$ on vector spreading was also detected in the BT4C cells (Fig. 9). This was demonstrated with both fluorescence microscopy (Figs. 8A and 9A) and flow cytometry (Figs. 8B and 9B).

\section{Discussion}

Propagation by two different mechanisms. According to the present study, it seems that Sindbis vectors may acquire propagation competence by two different mechanisms: (i) recombination leading to wild-type reversion and (ii) co-infection with vector shells containing unspecifically packaged helper RNA leading to local non-cytopathic spreading.

Serial passage assay based on observation of CPE is a sensitive method for specific detection of propagation-competent viruses generated upon Sindbis vector production due to recombination and wild-type reversion of viral RNA. However, in the case of the Sindbis split helper vector, clusters of marker gene-expressing cells were frequently found without associated CPE suggesting that this type of assay was not sufficiently sensitive for detection of local non-cytopathic spreading.

Recombination leading to wild-type reversion. The recombination sites were characterized using a PCR-based method, followed by sequencing of the PCR products. The results showed that one primer pair analysis of virus isolated from a single plaque with any of the primer pairs used often gives rise to multiple PCR products that represent different recombination sites. This may be related to the high frequency of recombination events, which enables rapid evolution of propagation-competent vectors. Recombinations were found to lead to restored wild-type sequences. On the other hand, many of the detected recombination sites disrupted both the structural and non-structural open reading frames. These recombinants may play a role as defective interfering RNAs, i.e. helper dependent deletion mutants of the parental virus genome which are capable of interfering with the virus replication (33).

According to the present study, TK-GFP transgene expression was often lost upon passaging of the propagation-competent vectors. Propagation-competent viruses that did not carry the functional TK-GFP transgene expression cassette had a selection advantage over those expressing the transgene. This observation is in line with the results of Weiss and Schlesinger (25) with the recombinant genomes that emerged due to recombination events between Sindbis replicon and helper RNAs. The recombinant genomes larger 


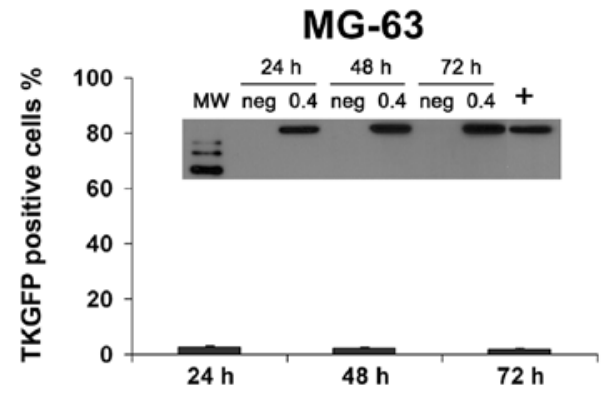

Saos-2

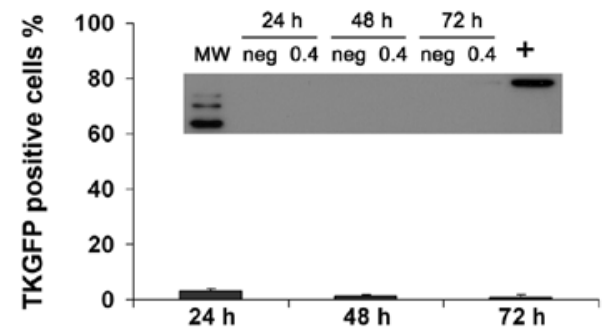

$\mathrm{U}-2-\mathrm{OS}$

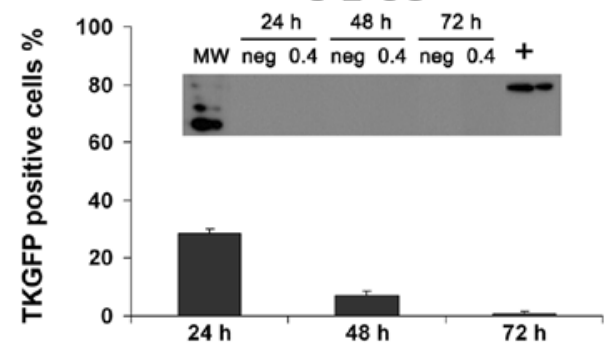

TE-671

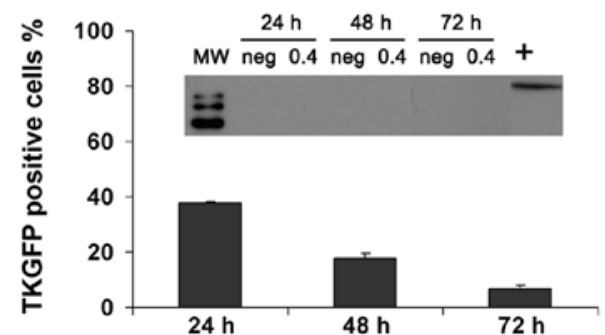

BT4C

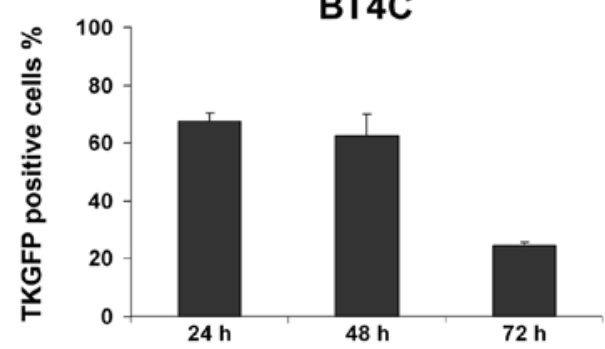

Figure 7. Transduction efficiency and type I IFN response at 24,48 and $72 \mathrm{~h}$ after transduction of the tumor cell lines with the Sindbis-TKGFP split helper vector at MOI 0.4. Transduction efficiencies are shown as proportions of TKGFP transgene-expressing cells analyzed by FACS. Western blot analysis of the expression of the 76-kDa MxA protein was used for detection of the type I IFN response.

than the wild-type Sindbis genome were unstable and finally evolved to the same size as the wild-type genome. Wild-type
A IFN U/ml
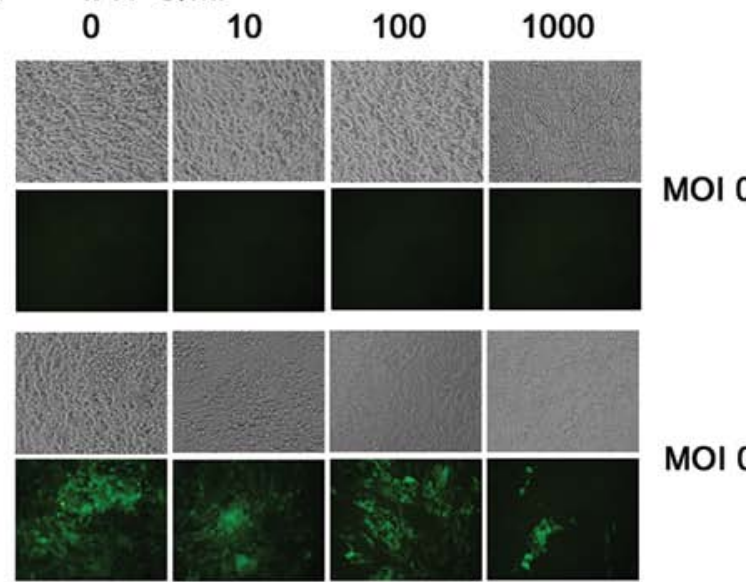

MOI 0.005
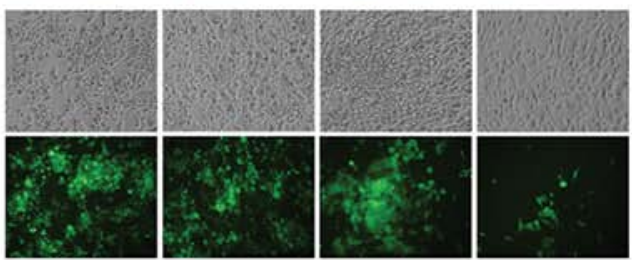

MOI 0.05
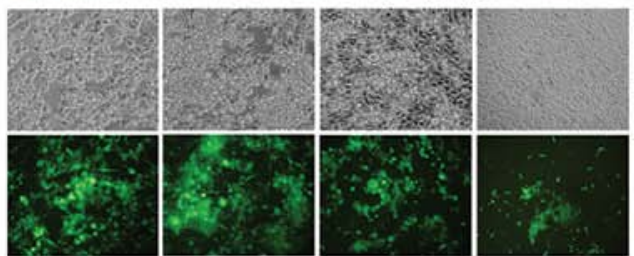

MOI 0.5

B

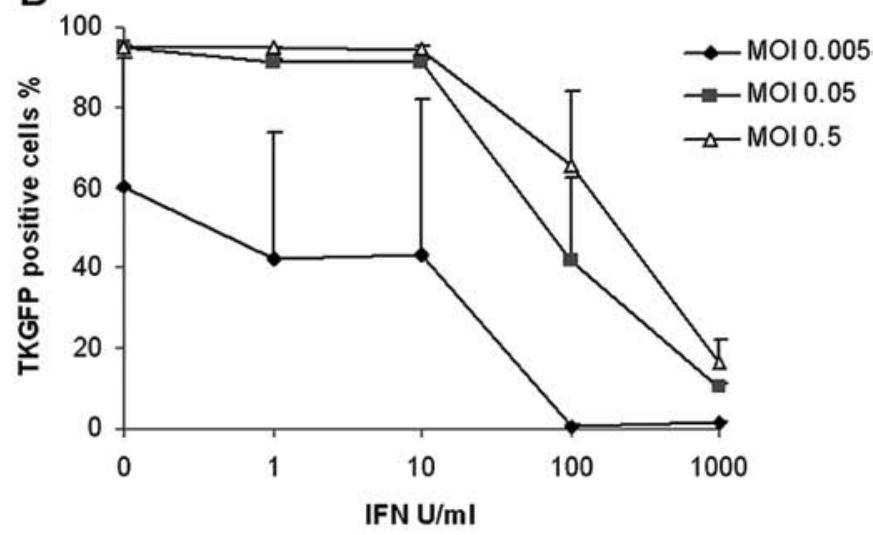

Figure 8. Human IFN- $\alpha$ efficiently suppresses spreading of the SindbisTKGFP split helper vector in BHK-21 cell cultures as detected by (A) fluorescence microscopy or (B) flow cytometry.

Sindbis virus has a genomic RNA of $11.7 \mathrm{~kb}(8)$. In the case that recombinations occur leading to the formation of a propagation-competent virus genome from the replicon and DH-BB helper or one $(\operatorname{Crrv} \Delta 3)$ or both components of the split helper RNA, the resulting recombinant virus genome can be markedly larger than the wild-type Sindbis genome. The Sindbis-TKGFP replicon RNA (10.28 kb) and the DH-BB helper RNA ( $4.8 \mathrm{~kb}$ ) have together a size of $\sim 15.1 \mathrm{~kb}$. The total size of Sindbis-TKGFP replicon RNA together with both split helper components CSin $(2.05 \mathrm{~kb})$ and $\operatorname{Crv} \Delta 3(4.75 \mathrm{~kb})$ is $\sim 17.1 \mathrm{~kb}$. In such cases, a strong selection pressure towards a smaller wild-type virus-like genome size exists. 


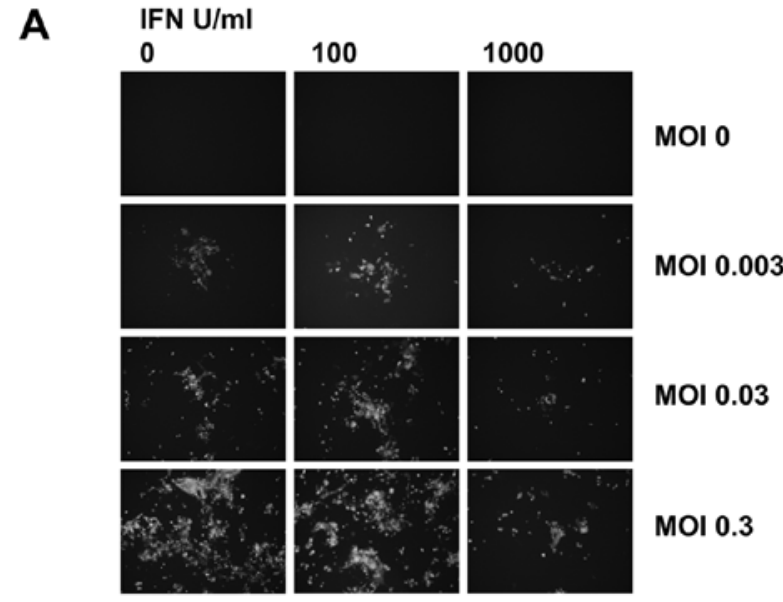

B

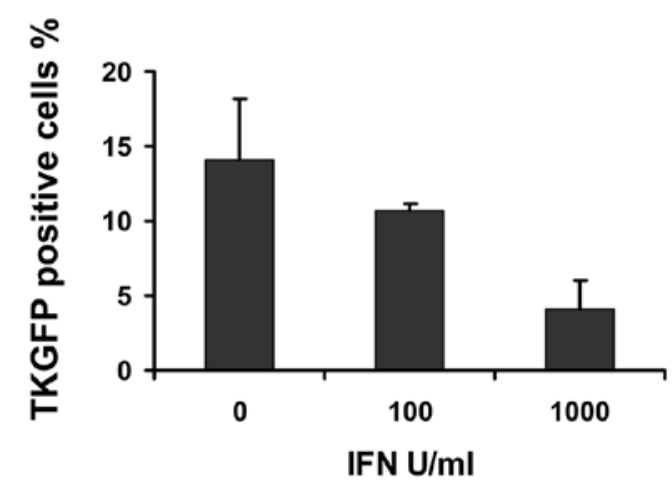

Figure 9. Suppression of the Sindbis-TKGFP split helper vector spreading in BT4C cell cultures with human IFN- $\alpha$ as detected by (A) fluorescence microscopy or (B) flow cytometry.

When Sindbis vectors are produced with the split helper packaging system, a two-step process is required for generation of the full-length Sindbis genome (23). First, recombination between the replicon and one of the split helper RNA components takes place, followed by recombination with the second component. In case that replicon-CSin helper recombinants are formed, the resulting recombinant genome is dependent on simultaneous transmission of the Crrv $\Delta 3$ helper RNA that is non-specifically packaged in the vector particles. This was previously demonstrated when only the replicon and CSin helper were used for vector production; infective vector particles were not formed when the Crrv $\Delta 3$ helper was missing (20). However, when the replicon was supported with the Crrv $\Delta 3$ helper without the presence of the CSin helper, low titers of infective and locally transmissive vectors were generated (20) and therefore we propose that replicon-Crrv $\Delta 3$ recombinants are not dependent on co-transmission of the CSin helper RNA. Still, CSin helper RNA that codes for Sindbis capsid protein could promote more potent formation of vector particles and enhanced spreading.

Local non-cytopathic spreading. Local non-cytopathic spreading may be related to recombinants that are strongly attenuated and almost non-viable due to deletions or some other type of fatal changes in the non-structural or structural open reading frames. Alternatively, it could be attributable to non-specific co-packaging of helper RNAs into repliconcontaining vector particles that is too inefficient to maintain a wild-type virus-like transmission cycle or co-infection with replicon and helper RNAs or replicon-CSin recombinants and Crrv $\Delta$ helper packaged into separate vector particles. Our data suggest that recombination is not necessarily required for vector propagation and plaque formation, as PCR analysis of some of the Sindbis split helper plaques detected no recombination sites.

If the two components of a bi-partite genome are packaged into separate particles, high MOIs would be essential for continued survival (24). The observation that the spreading foci are often lost during the continuous passage supports the hypothesis that the local spreading of Sindbis-TKGFP split helper vectors could be mainly based on co-infection with replicon and helper RNAs or replicon-CSin recombinant and Crrv $\Delta 3$ helper preferentially packaged in separate vector particles. A decrease in MOI after passage could be fatal to co-infection-based vector spreading.

Transduction efficiency and local spreading. BT4C, TE-671 and U-2-OS cells showed the highest proportions of TKGFP transgene-expressing cells of the 5 cell lines studied (Fig. 7). The local spreading of Sindbis virus vectors produced with the split helper system was detected in these 3 cell lines, while in the other 2 cell lines tested, we did not detect any spreading foci and the gene transfer efficiencies were very low. The capacity of the Sindbis-TKGFP split helper vector to spread locally in the target cells appears to have a major impact on its ability to elicit an effective gene transfer. The amount of primary positive cells after transduction as well as subsequent vector spreading are both affected by the repertoire of receptors expressed on the cell surface. This usually differs between distinct cell types. However, also the intracellular environment and host antiviral responses may have a strong influence on the vector performance.

Utilization of propagation-competent Sindbis vectors. The propagation-competent viruses that are present in Sindbis $\mathrm{DH}-\mathrm{BB}$ vector preparations could potentially function as oncolytic vectors, selectively propagating in malignant cells and leading to specific tumor cell death. In general, when propagation-competent virus vectors are used for gene transfer, vector propagation in tumor cells can eventually lead to widespread expression of the transgene in tumors despite the low initial transduction efficiency (34), for example, after systemic delivery of relatively low doses of vector compared to the number of cells in the tumor. Sindbis virus vectors capable of tumor selective propagation, especially vectors carrying transgenes that induce or enhance tumor-specific immune responses [for example IL-12, that was found to enhance antitumor effect of Sindbis vectors produced with the DH-BB helper (3)], could be promising agents for the treatment of malignant tumors. However, due to the labile nature of RNA virus genomes, propagative Sindbis vectors often evolve towards the wild-type, expelling such transgenes which do not offer a selection advantage compared to the wild-type genome. Clearly, in the case of propagation-competent oncolytic alphavirus vectors, safety issues should be carefully evaluated due to the unstable nature of the virus genome, typical to RNA viruses in general. Nevertheless, attenuated propagation-competent RNA viruses have been widely used 
in humans throughout the world for vaccination purposes. Almost complete eradication of polio using oral poliovirus vaccine is a landmark of the successful use of attenuated propagation-competent vaccine strains (35). However, live attenuated poliovirus vaccine strains are capable of effective uncontrolled spreading to unvaccinated subjects as well as capable of undergoing mutations leading to restored neurovirulence (35).

In the production of propagation-incompetent Sindbis virus vectors, it appears unlikely that splitting the helper RNA into several parts would lead to complete elimination of the contaminating propagation-competent viruses, due to the ease of recombination between Sindbis viral RNAs. It has been demonstrated that transfection of two non-overlapping and non-replicative RNA precursors representing the two halves of the Sindbis virus genome, one including the non-structural and the other the structural open reading frame, undergo recombination leading to the formation of full-length viral genome and production of infectious viruses (36). At present, one successful strategy to produce transmission incompetent alphavirus vectors is to modify the vector envelope in a way that vectors need to be pretreated before use to restore their infectivity (37). Additionally, to prevent formation of propagation-competent Sindbis virus during vector production, a similar approach as used for the construction of the SFV split helper RNA could be utilized (38). This involves modification of the capsid gene to abolish its self-cleaving activity. Thereby, recombination events between the replicon and split helper components cannot directly lead to wild-type reversion of the virus. However, our observation that propagation-competent vectors are formed also when only Crrv $\Delta 3$ RNA but not the Csin component of the split helper RNA is used for packaging of the replicon suggests that this modification may not totally abolish formation of propagation-competent virus-like particles. Still, vectors capable of subtle propagation due to co-infection with helper RNA-containing vector particles in the absence of wild-type reversion could serve as a tool for enhanced therapeutic gene transfer.

Suppression of vector propagation by type I IFN response. The 67-kDa laminin receptor is used by Sindbis for virus entry. This receptor is highly conserved among different species including invertebrates and vertebrates and is the most important receptor for the Sindbis virus expressed in mammalian cells (39). The $67-\mathrm{kDa}$ laminin receptor is frequently overexpressed in cancer cells, especially in metastatic tumors (40-42), and the tumor-targeting properties of Sindbis virus vectors have been suggested to result from utilization of this receptor $(2,3,43)$. However, Unno et al $(7)$ studied Sindbis AR339 strain as an oncolytic virus and found that normal keratinocytes also expressed high levels of the 67-kDa laminin receptor but were resistant to AR339 strain infection and subsequent induction of apoptosis whereas human ovarian and cervical cancer cells were susceptible both to virus propagation and to infection-induced apoptosis. Therefore, other mechanisms in addition to overexpression of the $67-\mathrm{kDa}$ laminin receptor are probably involved in the tumor selectivity of Sindbis virus. One possible mechanism of tumor selectivity is the sensitivity of Sindbis virus to type I IFNs. Tumor cells frequently have defective IFN pathways, because in addition to antiviral effects, the IFN-mediated signaling cascade can lead to growth inhibitory and apoptotic signals (44). Additionally, it has been shown that dependence on defects in IFN pathways in tumor cells can mediate tumor selectivity of an oncolytic virus, for example in the case of oncolytic vesicular stomatitis virus (45).

We used the IFN-induced protein MxA as a biomarker for the type I IFN response. Mx proteins are highly conserved large GTPases that have been found in all vertebrate species studied to date (27). According to our results, Sindbis virus vectors produced with the split helper system could not induce a detectable type I IFN response in TE-671 and U-2-OS cells, which were also the cell lines most permissive for transduction and local spreading of the vector. In contrast, MG-63 cells are known to respond with a vigorous IFN production to a variety of stimuli (46). In these cells, the few TKGFP-expressing cells detected with fluorescence microscopy usually appeared to be non-viable, and a strong MxA response was detected after transduction with the Sindbis virus vector. However, in Saos-2 cell cultures, the number of transgene-expressing cells was very low at all time-points, but no $\mathrm{MxA}$ protein accumulation was detected. This supports the hypothesis that vector spreading is affected by multiple independent factors in intracellular environment as well as the type of receptors expressed in the target cells. Efficient local spreading of the Sindbis-TKGFP split helper vector was demonstrated also in BT4C rat glioma cells. However, the human MxA antibody could not be used for detection of type I IFN response in rat cells because of the differences between human and rat $\mathrm{Mx}$ proteins. Therefore, we verified the negative impact of type I IFN response to vector propagation in BT4C cells by adding IFN- $\alpha$-containing growth medium to the transduced cells.

In this study, we demonstrated that extensive spreading of the Sindbis-TKGFP split helper vectors in BHK-21 cells deficient of IFN synthesis (32) were suppressed with administration of IFN- $\alpha$ to the cells. Double stranded RNA produced during viral replication is a potent inducer of type I IFNs in infected cells (27) and it has been proposed that the wild-type Sindbis virus suppresses host type I IFN responses by shutting down both host cell transcription and translation (47). In addition, one of the Sindbis non-structural proteins, nsP2, plays a role in the suppression of IFN production (48). These strategies to circumvent the negative impacts of IFNs help Sindbis virus to hide from the host antiviral defense mechanisms. However, it has been demonstrated that administration of IFN- $\alpha / \beta$ protects adult mice from fatal Sindbis viral infection (49). Therefore, the sensitivity for IFN could be a potentially important mechanism for controlling the vector propagation.

In conclusion, Sindbis vector preparations produced with the DH-BB helper RNA contain full-length Sindbis genomic RNA comprising both non-structural and structural protein encoding domains. The formation of propagation-competent virus genome via recombination events was markedly reduced but not completely prevented by using split helper RNA, in which the structural genes are divided into two separate helper RNAs.

The non-pathogenic Sindbis AR339 strain (7) and Sindbis vectors produced using a method allowing frequent formation of propagation-competent virus were shown to effectively 
target and kill tumor cells after systemic delivery in various animal models (3). Several studies indicate that propagation of Sindbis virus is sensitive to type I IFNs. In our study, we found that spreading of Sindbis split helper vectors was effectively suppressed by a type I IFN response. Previous research has shown that type I IFNs have a protective effect against Sindbis virus infection in vivo (49). Therefore, propagation-competent Sindbis vectors or oncolytic Sindbis viruses may be effectively controlled by administration of type I IFNs to prevent potential adverse effects.

\section{Acknowledgements}

This study was financially supported by the Finnish Medical Foundation and the North-Savo Regional Fund of the Finnish Cultural Foundation (grants to A.H.). We want to thank Dr Outi Rautsi for her skillful technical assistance; Kati Pulkkinen and Dr Anne Uimari for the practical advice concerning PCR; Docent Tero Ahola for the valuable comments; and Professor Ilkka Julkunen (Department of Viral Diseases and Immunology, National Public Health Institute, Finland) for the MxA antibody used in the western blot analyses.

\section{References}

1. Hurtado A, Tseng JC and Meruelo D: Gene therapy that safely targets and kills tumor cells throughout the body. Rejuvenation Res 9: 36-44, 2006.

2. Tseng JC, Hurtado A, Yee H, Levin B, Boivin C, Benet M, Blank SV, Pellicer A and Meruelo D: Using sindbis viral vectors for specific detection and suppression of advanced ovarian cancer in animal models. Cancer Res 64: 6684-6692, 2004

3. Tseng JC, Levin B, Hurtado A, Yee H, Perez de Castro I, Jimenez M, Shamamian P, Jin R, Novick RP, Pellicer A and Meruelo D: Systemic tumor targeting and killing by Sindbis viral vectors. Nat Biotechnol 22: 70-77, 2004.

4. Zhang J, Frolov I and Russell SJ: Gene therapy for malignant glioma using Sindbis vectors expressing a fusogenic membrane glycoprotein. J Gene Med 6: 1082-1091, 2004.

5. Mettler NE, Clarke DH and Casals J: Virus inoculation in mice bearing Ehrlich ascitic tumors: antigen production and tumor regression. Infect Immun 37: 23-27, 1982.

6. Wollmann G, Tattersall P and van den Pol AN: Targeting human glioblastoma cells: comparison of nine viruses with oncolytic potential. J Virol 79: 6005-6022, 2005.

7. Unno Y, Shino Y, Kondo F, Igarashi N, Wang G, Shimura R, Yamaguchi T, Asano T, Saisho H, Sekiya S and Shirasawa H: Oncolytic viral therapy for cervical and ovarian cancer cells by Sindbis virus AR339 strain. Clin Cancer Res 11: 4553-4560, 2005.

8. Strauss JH and Strauss EG: The alphaviruses: gene expression, replication, and evolution. Microbiol Rev 58: 491-562, 1994.

9. Kurkela S, Manni T, Myllynen J, Vaheri A and Vapalahti O: Clinical and laboratory manifestations of Sindbis virus infection: prospective study, Finland, 2002-2003. J Infect Dis 191: 1820-1829, 2005.

10. Kurkela S, Manni T, Vaheri A and Vapalahti O: Causative agent of Pogosta disease isolated from blood and skin lesions. Emerg Infect Dis 10: 889-894, 2004

11. Laine M, Luukkainen R and Toivanen A: Sindbis viruses and other alphaviruses as cause of human arthritic disease. J Intern Med 256: 457-471, 2004.

12. Niklasson B, Espmark A, LeDuc JW, Gargan TP, Ennis WA, Tesh RB and Main AJ Jr: Association of a Sindbis-like virus with Ockelbo disease in Sweden. Am J Trop Med Hyg 33: 1212-1217, 1984

13. Greene IP, Wang E, Deardorff ER, Milleron R, Domingo E and Weaver SC: Effect of alternating passage on adaptation of sindbis virus to vertebrate and invertebrate cells. J Virol 79: 14253-14260, 2005.
14. Kerr PJ, Weir RC and Dalgarno L: Ross River virus variants selected during passage in chick embryo fibroblasts: serological, genetic, and biological changes. Virology 193: 446-449, 1993

15. Klimstra WB, Ryman KD and Johnston RE: Adaptation of Sindbis virus to BHK cells selects for use of heparan sulfate as an attachment receptor. J Virol 72: 7357-7366, 1998.

16. Smit JM, Waarts BL, Kimata K, Klimstra WB, Bittman R and Wilschut J: Adaptation of alphaviruses to heparan sulfate: interaction of Sindbis and Semliki forest viruses with liposomes containing lipid-conjugated heparin. J Virol 76: 10128-10137, 2002.

17. Domingo $\mathrm{E}$ and Holland JJ: RNA virus mutations and fitness for survival. Annu Rev Microbiol 51: 151-178, 1997.

18. Hajjou M, Hill KR, Subramaniam SV, Hu JY and Raju R: Nonhomologous RNA-RNA recombination events at the 3 nontranslated region of the Sindbis virus genome: hot spots and utilization of nonviral sequences. J Virol 70: 5153-5164, 1996.

19. Bredenbeek PJ, Frolov I, Rice CM and Schlesinger S: Sindbis virus expression vectors: packaging of RNA replicons by using defective helper RNAs. J Virol 67: 6439-6446, 1993.

20. Ketola A, Schlesinger S and Wahlfors J: Properties of Sindbis virus vectors produced with a chimeric split helper system. Int J Mol Med 15: 999-1003, 2005.

21. Lu X and Silver J: Transmission of replication-defective Sindbis helper vectors encoding capsid and envelope proteins. J Virol Methods 91: 59-65, 2001.

22. Wahlfors JJ, Zullo SA, Loimas S, Nelson DM and Morgan RA: Evaluation of recombinant alphaviruses as vectors in gene therapy. Gene Ther 7: 472-480, 2000.

23. Frolov I, Frolova E and Schlesinger S: Sindbis virus replicons and Sindbis virus: assembly of chimeras and of particles deficient in virus RNA. J Virol 1997 71: 2819-2829, 1997.

24. Geigenmüller-Gnirke U, Weiss B, Wright R and Schlesinger S: Complementation between Sindbis viral RNAs produces infectious particles with a bipartite genome. Proc Natl Acad Sci USA 88: 3253-3257, 1991.

25. Weiss BG and Schlesinger S: Recombination between Sindbis virus RNAs. J Virol 65: 4017-4025, 1991.

26. Katze MG, He Y and Gale M Jr: Viruses and interferon: a fight for supremacy. Nat Rev Immunol 2: 675-687, 2002.

27. Goodbourn S, Didcock L and Randall RE: Interferons: cell signalling, immune modulation, antiviral response and virus countermeasures. J Gen Virol 81: 2341-2364, 2000.

28. Laerum OD, Rajewsky MF, Schachner M, et al: Phenotypic properties of neoplastic cell lines developed from fetal rat brain cells in culture after exposure to ethylnitrosourea in vivo. $Z$ Krebsforsch Klin Onkol Cancer Res Clin Oncol 89: 273-295, 1977.

29. Rautsi O, Lehmusvaara S, Salonen T, Häkkinen K, Sillanpää M, Hakkarainen T, Heikkinen S, Vähäkangas E, Ylä-Herttuala S, Hinkkanen A, Julkunen I, Wahlfors J and Pellinen R: Type I interferon response against viral and non-viral gene transfer in human tumor and primary cell lines. J Gene Med 9: 122-135, 2007.

30. Ronni T, Matikainen S, Sareneva T, Melén K, Pirhonen J, Keskinen P and Julkunen I: Regulation of IFN-alpha/beta, MxA, 2',5'-oligoadenylate synthetase, and HLA gene expression in influenza A-infected human lung epithelial cells. J Immunol 158: 2363-2374, 1997.

31. Ronni T, Melén K, Malygin A and Julkunen I: Control of IFN-inducible MxA gene expression in human cells. J Immunol 150: 1715-1726, 1993 .

32. Schlesinger S and Dubensky TW: Alphavirus vectors for gene expression and vaccines. Curr Opin Biotechnol 10: 434-439, 1999.

33. Monroe SS and Schlesinger S: Common and distinct regions of defective-interfering RNAs of Sindbis virus. J Virol 49: 865-872, 1984

34. Galanis E, Vile R and Russell SJ: Delivery systems intended for in vivo gene therapy of cancer: targeting and replication competent viral vectors. Crit Rev Oncol Hematol 38: 177-192, 2001.

35. Kew OM, Wright PF, Agol VI, Delpeyroux F, Shimizu H, Nathanson N and Pallansch MA: Circulating vaccine-derived polioviruses: current state of knowledge. Bull World Health Organ 82: 16-23, 2004.

36. Raju R, Subramaniam SV and Hajjou M: Genesis of Sindbis virus by in vivo recombination of nonreplicative RNA precursors. J Virol 69: 7391-7401, 1995. 
37. Berglund P, Sjöberg M, Garoff H, Atkins GJ, Sheahan BJ and Liljeström P: Semliki Forest virus expression system: production of conditionally infectious recombinant particles. Biotechnology 11: 916-920, 1993.

38. Smerdou C and Liljeström P: Two-helper RNA system for production of recombinant Semliki forest virus particles. J Virol 73: 1092-1098, 1999.

39. Wang KS, Kuhn RJ, Strauss EG, Ou S and Strauss JH: Highaffinity laminin receptor is a receptor for Sindbis virus in mammalian cells. J Virol 66: 4992-5001, 1992.

40. Castronovo V: Laminin receptors and laminin-binding proteins during tumor invasion and metastasis. Invasion Metastasis 13: $1-30,1993$.

41. Martignone S, Ménard S, Bufalino R, Cascinelli N, Pellegrini R, Tagliabue E, Andreola S, Rilke F and Colnaghi MI: Prognostic significance of the 67-kilodalton laminin receptor expression in human breast carcinomas. J Natl Cancer Inst 85: 398-402, 1993.

42. Sobel ME: Differential expression of the $67 \mathrm{kDa}$ laminin receptor in cancer. Semin Cancer Biol 4: 311-317, 1993.

43. Tseng JC, Zanzonico PB, Levin B, Finn R, Larson SM and Meruelo D: Tumor-specific in vivo transfection with HSV-1 thymidine kinase gene using a Sindbis viral vector as a basis for prodrug ganciclovir activation and PET. J Nucl Med 47: 1136-1143, 2006
44. Everts B and van der Poel HG: Replication-selective oncolytic viruses in the treatment of cancer. Cancer Gene Ther 12: 141-161, 2005.

45. Stojdl DF, Lichty B, Knowles S, Marius R, Atkins H, Sonenberg N and Bell JC: Exploiting tumor-specific defects in the interferon pathway with a previously unknown oncolytic virus. Nat Med 6: 821-825, 2000.

46. Billiau A, Edy VG, Heremans H, Van Damme J, Desmyter J, Georgiades JA and De Somer P: Human interferon: mass production in a newly established cell line, MG-63. Antimicrob Agents Chemother 12: 11-15, 1977.

47. Gorchakov R, Frolova E and Frolov I: Inhibition of transcription and translation in Sindbis virus-infected cells. J Virol 79: 9397-9409, 2005.

48. Frolova EI, Fayzulin RZ, Cook SH, Griffin DE, Rice CM and Frolov I: Roles of nonstructural protein nsP2 and Alpha/Beta interferons in determining the outcome of Sindbis virus infection. J Virol 76: 11254-11264, 2002.

49. Ryman KD, Klimstra WB, Nguyen KB, Biron CA and Johnston RE: Alpha/beta interferon protects adult mice from fatal Sindbis virus infection and is an important determinant of cell and tissue tropism. J Virol 74: 3366-3378, 2000. 